\title{
Clinical and sociodemographic correlates of suicidality in patients with major depressive disorder from six Asian countries
}

\author{
Ah-Young Lim', Ah-Rong Lee ${ }^{1}$, Ahmad Hatim², Si Tian-Mei ${ }^{3}$, Chia-Yih Liư ${ }^{4}$ Hong Jin Jeon ${ }^{5}$, Pichet Udomratn ${ }^{6}$, \\ Dianne Bautista ${ }^{7,8}$, Edwin Chan ${ }^{7,8}$, Shen-Ing Liu' ${ }^{9}$, Hong Choon Chua ${ }^{10}$, Jin Pyo Hong ${ }^{1 *}$ and For the MD RAN
}

\begin{abstract}
Background: East Asian countries have high suicide rates. However, little is known about clinical and sociodemographic factors associated with suicidality in Asian populations. The aim of this study was to evaluate the factors associated with suicidality in patients with major depressive disorder (MDD) from six Asian countries.

Methods: The study cohort consisted of 547 outpatients with MDD. Patients presented to study sites in China $(n=114)$, South Korea $(n=101)$, Malaysia $(n=90)$, Singapore $(n=40)$, Thailand $(n=103)$, and Taiwan $(n=99)$. All patients completed the Mini-International Neuropsychiatric Interview (MINI), the Montgomery-Asberg Depression Rating Scale (MADRS), the Global Severity Index(SCL-90R), the Fatigue Severity Scale, the 36-item short-form health survey, the Sheehan Disability Scale, and the Multidimensional Scale of Perceived Social Support (MSPSS). Patients were classified as showing high suicidality if they scored $\geq 6$ on the MINI suicidality module. Multivariate logistic regression analysis was used to examine sociodemographic and clinical factors related to high suicidality.

Results: One hundred and twenty-five patients were classed as high suicidality. Unemployed status (adjusted odds ratio [OR] 2.43, $p<0.01$ ), MADRS score (adjusted OR 1.08), $\mathrm{p}<0.001$, and GSI (SCL-90R) score (adjusted OR 1.06, $p<0.01$ ) were positively related to high suicidality. Hindu (adjusted OR 0.09, $p<0.05$ ) or Muslim (adjusted OR 0.21, $p<0.001$ ) religion and MSPSS score (adjusted OR 0.82, $p<0.05$ ) were protective against high suicidality.
\end{abstract}

Conclusions: A variety of sociodemographic and clinical factors were associated with high suicidality in Asian patients with MDD. These factors may facilitate the identification of MDD patients at risk of suicide.

Keywords: Suicide, Major depressive disorder, Risk factor, Social support

\section{Background}

It is estimated that approximately 1 million people worldwide commit suicide annually, and about $60 \%$ of these people are from Asian countries [1,2]. The suicide rate in East Asian countries, including South Korea, Japan, and China, is especially high. According to a 2011 report from the World Health Organization's worldwide initiative for the prevention of suicide, Korea ranked third, Japan ranked ninth, and China ranked twenty-fourth out of 105 countries for suicide rate [3]. Despite such compelling figures, suicide is relatively under-researched, and preventive

\footnotetext{
* Correspondence: jphong@amc.seoul.kr

'Department of Psychiatry, Asan Medical Center, Ulsan University College of Medicine, Seoul, South Korea

Full list of author information is available at the end of the article
}

approaches in Asian countries are limited compared to those in European and American countries [4-6].

Studies have consistently reported that major depressive disorder (MDD) is closely related to suicide, suicidal ideation, suicide planning, and suicide attempts and is a significant risk factor for suicide $[7,8]$. According to previous studies, severe or extended depression [9-12], advanced age [9], low level of education [13], low level of social support and occupational functioning $[9,11]$, lack of a partner $[11,12]$, current alcohol dependence or substance abuse $[9,11,13]$, negative life events [14], and impulsivity and hostility $[10,15,16]$ have all been reported to be risk factors for suicide attempts in MDD. However, the etiology of MDD is extremely complicated, and the generalization of suicide risk factors is difficult because 
of differences between studies in the populations studied and the methods employed. In particular, the profiles of risk and protective factors of suicide in Asian countries differ from those of Western countries [10].

Recently, we reported that melancholic features and hostility were associated with suicidal risk in MDD patients from six Asian countries [17]. However, the cited study mainly focused on melancholic features and did not examine important factors such as religion, functional impairment, and poor social support. Interestingly, the prevalence of MDD is lower in East Asian countries than in European and American countries, but suicide rates are higher $[18,19]$. This suggests that in East Asian countries, various clinical, social, and cultural factors, including religious practices, may be related to suicide in addition to psychiatric disorders such as MDD.

Although several studies have provided information on the risk factors for suicide in Asian countries [20-22], comprehensive examination on the characteristics of suicide in MDD by multi-country comparative analysis was few. Accordingly, the aim of the present study was to evaluate the sociodemographic and clinical factors related to suicidality in MDD patients from six Asian countries (China, South Korea, Malaysia, Singapore, Taiwan, and Thailand).

\section{Methods}

\section{Study design and settings}

This study uses data from the Study on the Aspects of Asian Depression (SAAD) [20]. The participants and method of the present study are the same as those of the Recognizing Ethnic Differences in Depression (REDD) study [17], a multi-country, cross-sectional, observational study of depression in clinical settings carried out during 2008-2011. Thirteen study sites were established across six Asian countries: China, South Korea, Malaysia, Singapore, Taiwan, and Thailand. The study sites were as follows: Beijing Anding Hospital (Beijing, China), Institute of Mental Health (Beijing, China), Shanghai Mental Health Center (Shanghai, China), Samsung Medical Center (Seoul, Korea), Asan Medical Center (Seoul, Korea), Kyungpook National University Hospital (Daegu, Korea), Inha University Hospital (Incheon, Korea), University of Malaya Medical Center (Kuala Lumpur, Malaysia), Institute of Mental Health Woodbridge Hospital (Singapore), Chung Gang Memorial Hospital (Taoyan county, Taiwan), McKay Memorial Hospital (Taipei City, Taiwan), Maharaj Nakorn Chiang Mai Hospital (Chiang Mai, Thailand), and Prince of Songkla University (Songkla, Thailand). All study sites provided psychiatric care for the public or private sector. The study was approved by the Institutional Review Board or Ethics Committee of Asan Medical Center and each respective site.

\section{Participants}

Participants were prospectively enrolled in the study and were recruited from outpatients who were seeking psychiatric treatment at a study site. Individuals presenting for an intake appointment were approached by a study coordinator and informed about the study. After the study details had been fully explained, written informed consent was obtained from each participant. The inclusion criteria were as follows: i) age 18-65 years; ii) a positive response ("yes") to the Mini-International Neuropsychiatric Interview (MINI) [21] question A1 (depressed mood) and/or A2 (loss of interest); and iii) a diagnosis of MDD according to the DSM-IV criteria [22] that was assessed by the MINI. The exclusion criteria were as follows: i) unstable medical condition; ii) mood disorder due to medical conditions and/or substance abuse; iii) psychotic or bipolar disorder; iv) clinically significant cognitive impairment; v) treatment with psychotropic medication within the previous month; vi) treatment with a benzodiazepine within the previous week; and vii) treatment with a long-acting antipsychotic medication within the previous 3 months. All other psychiatric and comorbid conditions were permitted.

The following sociodemographic characteristics were recorded: age, sex, marital status (married or co-habiting; widowed or divorced; never married), work status (employed; homemaker or student; unemployed), and education (none or primary; secondary or vocational; college). The following clinical characteristics were recorded: age at first onset, length of illness, number of past psychiatric hospitalizations, and depression severity.

\section{Assessment}

Participants completed several self-report questionnaires in the presence of the study coordinator. A face-to-face diagnostic evaluation was then conducted with the site investigator before the participant met with their treating clinician. Data collection was accomplished in a single visit. Suicidality is the likelihood of an individual completing suicide and include suicidal ideation, selfinjurious behavior, suicide attempts, and suicide despite their very different consequences for the patient. In the present study, the term "suicidality" includes the full spectrum of suicidal thoughts (thoughts about wanting to be dead) and suicidal acts (previous self-destructive behaviors [23] with at least some intent to end one's life), in keeping with a previous study [23].

Suicidal ideation and behaviors were assessed with the MINI suicidality module [21]. The MINI suicidality module was used to rate the risk of suicide. The module comprises 6 questions about suicidal ideation and behavior: (1-5) In the past month, did you 1. think you would be better off dead or wish you were dead? (1 point), 2. want to harm yourself? ( 2 points), 3 . think about suicide? 
(6 points), 4. have a suicide plan? (10 points), 5. attempt suicide? (10 points). 6 . In your life, have you ever made a suicide attempt? (4 points). The total number of points is used to classify the current suicide risk on three levels. Scores ranging from 1 to 5 are considered low risk, from 6 to 9 are moderate, and above 10 are high. According to the previous study investigating predictive value of MINI suicidality module, the sensitivity and specificity for suicide attempts after 12 months in patients with moderate-risk MINI sum scores are 0.73 and 0.62 , and with high-risk, the MINI sum scores are 0.61 and 0.75 [24]. The positive and negative likelihood ratios for patients with moderate-risk sum scores are 1.9 (95\% CI, 1.1-3.2) and 0.44 (95\% CI, 0.26-0.74), respectively, and in patients with high-risk sum scores, they are 2.4 (95\% CI, 1.9-3.0) and 0.52 (95\% CI, 0.42-0.65) [24]. In this study, depression severity was assessed with the MontgomeryAsberg Depression Rating Scale (MADRS) [25], psychiatric symptoms were assessed with the Global Severity Index(GSI provided by SCL-90-R) [26], fatigue severity was assessed with the Fatigue Severity Scale (FSS) [27], health-related quality of life was assessed with the 36 item short form health survey (SF-36) [28], disability was assessed with the Sheehan Disability Scale (SDS) [29], and perceived social support was assessed with the Multidimensional Scale of Perceived Social Support (MSPSS) [30].

\section{Statistical analysis}

Participants were classified as low suicidality (score $\leq 5$ on the MINI suicidality module) or high suicidality (score $\geq 6$ on the MINI suicidality module). Country, religion, age group, sex, marital status, work status, and education were compared across low and high suicidality groups using Pearson's chi-square tests. Age, age at first onset, length of illness, the number of past hospitalizations, MADRS score, GSI score, FSS score, SF-36's total and subscales (bodily pain, emotional wellbeing, general health, role limitation due to emotional health, role limitation due to physical functioning, social functioning, vitality) score, SDS's total and subscales (work and school, social and leisure, family life) score, and MSPSS's total and subscales (family, friends, significant others) scores for low- and high-suicidality groups were compared using two-tailed Student's t-tests for normally distributed variables and Mann-Whitney U-tests for non-normally distributed variables. A stratified logistic regression model was used to investigate predictors of high risk of suicide after controlling for age, sex, years of education, religion, work status, and total MADRS, GSI, FSS, and MSPSS scores. To account for collinearity, the country was not included as an independent variable but as a stratum in the stratified logistic regression model, because its association with other variables such as religion and educational background were high. Independent variables that were analyzed included age, sex, education, religion, work status, history of hospitalization, total MADRS score, GSI of SCL-90-R score, total FSS score, and total MSPSS score. Variables significant $(\mathrm{p}<0.1)$ on univariate analysis were selected for inclusion in the multivariable model.

The null hypothesis was rejected at $\mathrm{p}<0.05$. The Statistical Package for the Social Sciences (SPSS) software, version 12.0, and SAS (version 9.3, Cary, NC) were used for all analyses.

\section{Results}

A total of 2,023 outpatients were screened for eligibility, and $637(31.5 \%)$ were eligible. Of the 637 outpatients that were eligible, 556 were enrolled in the study. The remaining 81 outpatients were not enrolled for the following reasons: 1$)$ refusal/unwillingness to cooperate $(\mathrm{n}=58)$; $2)$ insufficient patience to be interviewed $(n=14)$; or 3$)$ insufficient time to participate $(n=9)$. All participants were compensated for their time. The mean (SD) time taken for completion of the self-administered questionnaires was 35.8 (14.1) $\mathrm{min}$, and for face-to-face interview was 38.1 (13.8) $\mathrm{min}$. After the interviews, nine participants were excluded from further analysis because they had no MDD. The remaining 547 participants were included in the analysis. $125(22.9 \%)$ were classed as high suicidality (score $\geq 6$ on the MINI suicidality module) and 422 (77.1\%) were classed as low suicidality (score $\leq 5$ on the MINI suicidality module).

\section{Univariate analysis of sociodemographic and clinical factors}

There were significant differences in country $\left(\chi^{2}=45.62\right.$, $\mathrm{p}<0.001)$, religion $\left(\chi^{2}=12.57, \mathrm{p}=0.028\right)$, sex $\left(\chi^{2}=4.13\right.$, $\mathrm{p}=0.044)$, work status $\left(\chi^{2}=13.42, \mathrm{p}=0.001\right)$, and number of hospitalizations $(t=2.44, p=0.016)$ between low and high suicidality groups (Table 1 ). The highest proportion of patients classed as high suicidality occurred in South Korea (42.6\%), followed by Taiwan (31.3\%), China (21.9\%), and Singapore (17.5\%). There were no significant differences in age, marital status, education, age at first onset, and length of illness between low and high suicidality groups (Table 1$)$. The high-suicidality group had higher MADRS $(t=7.33, p<0.001)$, GSI $(t=$ 5.40, $\mathrm{p}<0.001)$, FSS $(\mathrm{Z}=-3.191, \mathrm{p}<0.001)$, and SDS scores $(\mathrm{t}=3.34, \mathrm{p}=0.001)$ and lower SF-36 $(\mathrm{t}=5.09, \mathrm{p}<0.001)$ and MSPSS scores $(t=3.97, \mathrm{p}<0.001)$ than did the lowsuicidality group (Table 2 ).

\section{Multivariate analysis for high suicidality}

In the logistic regression model religion, work status, MADRS score, and FSS scores were related to high suicidality in MDD patients (Table 3). Patients who were unemployed (adjusted odds ratio (OR) 2.50, 95\% confidence 
Table 1 Sociodemographic characteristics of major depressive disorder patients with low and high suicidality

\begin{tabular}{|c|c|c|c|c|c|c|c|}
\hline & \multicolumn{2}{|c|}{ Low suicidality $(n=422)$} & \multicolumn{2}{|c|}{ High suicidality $(n=125)$} & \multicolumn{3}{|c|}{ Comparison of low and high suicidality groups } \\
\hline & $n$ & $\%$ & $n$ & $\%$ & $x^{2}$ & $d f$ & $p$ value \\
\hline \multicolumn{8}{|l|}{ Country } \\
\hline China & 89 & 78.1 & 25 & 21.9 & 45.62 & 5 & $<0.001^{*}$ \\
\hline South Korea & 58 & 57.4 & 43 & 42.6 & & & \\
\hline Malaysia & 82 & 91.1 & 8 & 8.9 & & & \\
\hline Singapore & 33 & 82.5 & 7 & 17.5 & & & \\
\hline Thailand & 92 & 89.3 & 11 & 10.7 & & & \\
\hline Taiwan & 68 & 68.7 & 31 & 31.3 & & & \\
\hline \multicolumn{8}{|l|}{ Age group } \\
\hline $18-29$ years & 128 & 78.5 & 35 & 21.5 & 4.40 & 4 & $0.355^{*}$ \\
\hline 30-39 years & 86 & 71.7 & 34 & 28.3 & & & \\
\hline 40-49 years & 76 & 74.5 & 26 & 25.5 & & & \\
\hline $50-59$ years & 103 & 81.1 & 24 & 18.9 & & & \\
\hline $60-65$ years & 29 & 82.9 & 6 & 17.1 & & & \\
\hline \multicolumn{8}{|l|}{ Sex } \\
\hline Male & 160 & 82.1 & 35 & 17.9 & 4.13 & 1 & $0.044^{*}$ \\
\hline Female & 262 & 74.4 & 90 & 25.6 & & & \\
\hline \multicolumn{8}{|l|}{ Marital status } \\
\hline Married or co-habiting & 254 & 73.8 & 64 & 26.3 & 2.90 & 2 & 0.235 \\
\hline Widowed or divorced & 50 & 79.9 & 18 & 20.1 & & & \\
\hline Never married & 118 & 73.5 & 42 & 26.5 & & & \\
\hline \multicolumn{8}{|l|}{ Work status } \\
\hline Employed & 216 & 84.0 & 41 & 16.0 & 13.42 & 2 & $0.001^{*}$ \\
\hline Homemaker or student & 132 & 72.1 & 51 & 27.9 & & & \\
\hline Unemployed & 74 & 69.2 & 33 & 30.8 & & & \\
\hline \multicolumn{8}{|l|}{ Education } \\
\hline None or primary & 67 & 83.8 & 13 & 16.3 & 3.30 & 2 & 0.192 \\
\hline Secondary or vocational & 236 & 74.7 & 80 & 25.3 & & & \\
\hline College & 119 & 78.8 & 32 & 21.2 & & & \\
\hline Past hospitalization & & & & & 13.76 & 1 & $.001^{* *}$ \\
\hline None & 394 & 93.8 & 104 & 83.2 & & & \\
\hline Presence & 26 & 6.2 & 21 & 16.8 & & & \\
\hline \multicolumn{8}{|l|}{ Religion } \\
\hline No religion & 159 & 73.3 & 58 & 26.7 & 12.57 & 5 & $0.028^{*}$ \\
\hline Buddhist & 152 & $v$ & 39 & 20.4 & & & \\
\hline Christian & 50 & 69.4 & 22 & 30.6 & & & \\
\hline Hindu & 20 & 95.2 & 1 & 4.8 & & & \\
\hline Muslim & 34 & 89.5 & 4 & 10.5 & & & \\
\hline \multirow[t]{2}{*}{ Other } & 7 & 87.5 & 1 & 12.5 & & & \\
\hline & Mean (SD) & & Mean (SD) & & $\mathrm{t}$ & $d f$ & $\mathrm{p}$ value \\
\hline Age (years) & $39.9(13.4)$ & & $38.7(12.6)$ & & 0.89 & 545 & 0.376 \\
\hline Age at first onset (years) & $36.9(13.4)$ & & $34.8(12.8)$ & & 1.56 & 544 & 0.119 \\
\hline Length of illness (weeks) & $76.1(159.3)$ & & $90.2(174.8)$ & & 0.45 & 545 & 0.398 \\
\hline
\end{tabular}


Table 2 Clinical characteristics of major depressive disorder patients with low and high suicidality

\begin{tabular}{|c|c|c|c|c|c|}
\hline & \multirow[t]{2}{*}{ Low suicidality $(n=422)$} & \multirow[t]{2}{*}{ High suicidality $(n=125)$} & \multicolumn{3}{|c|}{ Comparison of low and high suicidality groups } \\
\hline & & & $t$ or $Z$ & $d f$ & $p$ value \\
\hline MADRS score & $27.78(7.96)$ & $33.58(7.14)$ & 7.33 & 545 & $<0.001^{* *}$ \\
\hline GSI (of SCL-90-R) score & $0.13(0.06)$ & $0.17(0.07)$ & 5.40 & 543 & $<0.001^{* *}$ \\
\hline FSS score & $4.92(1.47)$ & $5.42(1.22)$ & -3.19 & 236.19 & $0.001^{* *}$ \\
\hline SF-36 score & $376.7(124.1)$ & $311.9(126.8)$ & 5.09 & 542 & $<0.001^{* *}$ \\
\hline Bodily paint & $59.19(27.22)$ & $55.94(29.46)$ & -1.04 & 543 & .294 \\
\hline Emotional wellbeing & $33.52(18.15)$ & $24.29(16.89)$ & 5.05 & 544 & $<0.001^{* *}$ \\
\hline General health & $37.15(20.42)$ & $32.70(23.06)$ & 2.07 & 544 & $0.039^{*}$ \\
\hline $\begin{array}{l}\text { Role limitation due to } \\
\text { emotional healtht }\end{array}$ & $41.45(26.77)$ & $30.17(24.95)$ & -4.27 & 543 & $<0.001^{* *}$ \\
\hline $\begin{array}{l}\text { Role limitations due to } \\
\text { hysical healtht }\end{array}$ & $50.67(28.73)$ & $42.85(28.17)$ & -2.70 & 544 & $<0.001^{* *}$ \\
\hline Physical functioning & $79.83(22.37)$ & $69.82(25.44)$ & -4.14 & 180.48 & $<0.001^{* *}$ \\
\hline Social functioning & $46.77(24.87)$ & $40.02(25.90)$ & -2.63 & 544 & $0.008^{*}$ \\
\hline Vitality & $28.41(19.21)$ & $16.63(15.65)$ & -6.27 & 242.14 & $<0.001^{* *}$ \\
\hline SDS score & $16.52(8.08)$ & $19.22(7.73)$ & 3.34 & 545 & $0.001^{* *}$ \\
\hline Work/school & $6.23(2.29)$ & $7.34(2.55)$ & -3.46 & 203.59 & $0.001^{* *}$ \\
\hline Social/leisure & $5.64(3.00)$ & $6.52(2.84)$ & -2.92 & 544 & $0.003^{* *}$ \\
\hline Family life & $5.24(3.20)$ & $6.35(2.95)$ & -3.40 & 543 & $0.001^{* *}$ \\
\hline MSPSS score & $4.56(1.40)$ & $3.99(1.42)$ & 3.97 & 542 & $<0.001^{* *}$ \\
\hline Family & $4.89(1.65)$ & $4.18(1.87)$ & -3.64 & 180.60 & $<0.001^{* *}$ \\
\hline Friends & 4.35 (1.59) & $3.85(1.56)$ & 3.07 & 542 & $0.002^{* *}$ \\
\hline Significant others & $4.71(1.82)$ & $4.18(1.82)$ & -2.93 & 542 & $0.003^{* *}$ \\
\hline
\end{tabular}

†Reversely-coded variables. Higher score indicates better quality of life.

MADRS, Montgomery-Åsberg Depression Rating Scale; Global Severity Index(SCL-90-R, Symptoms Checklist Questionnaire-90-Revised); FSS, Fatigue Severity Scale; SF-36, Medical Outcome Survey Short Form-36; SDS, Sheehan Disability Scale; MSPSS, Multidimensional Scale of Perceived Social Support. ${ }^{*} P<0.05$.

${ }^{* *} P<0.01$.

interval (CI) 1.27-4.90), patient who had history of hospitalization(adjusted odds ratio (OR) 2.96, 95\% confidence interval (CI) 1.41-6.20), patients who had high MADRS score (adjusted OR 1.11, 95\% CI 1.07-1.15), and patients who had a high FSS score (crude OR 1.36, 95\% CI 1.151.61) had increased odds of being in the high suicidality group. The MSPSS score (adjusted OR 0.83, 95\% CI 0.700.98) was inversely associated with high suicidality. Age, sex, years of education, religion, and marital status were not significant in the model (Table 3 ).

\section{Discussion}

In the current study, MDD patients were categorized as low or high suicidality according to their score on the MINI suicidality module. Country, religion, sex, work status, depression severity (measured using MADRS), and the number of past hospitalizations differed between patients with low and high suicidality, but age, marital status, education level, age at first onset of MDD, and length of illness were similar in the two groups. In Malaysia and
Thailand, about $10 \%$ of MDD patients were classed as high suicidality, whereas in South Korea over $40 \%$ of MDD patients were classed as high suicidality. This is consistent with recent epidemiological studies on national suicide rates. The World Health Organization reported that suicide rates in East Asian countries such as South Korea and China were much higher than in Malaysia and Thailand [3], and the prevalence of suicidal behavior has consistently been reported to be high in South Korea [31]. Differences in the suicide rates in Asian countries are related to various factors including climate, religion, financial status, and availability of suicide methods [2]. For instance, South Korea and China experience more drastic weather changes than Thailand or Malaysia, and such changes may contribute to the high suicide rate [32]. Furthermore, the abrupt social changes and economic recession in East Asian countries is likely to have influenced the suicide rate.

In the present study, there was a significant relationship between religion and suicidality. Patients who were Hindu 
Table 3 Stratified logistic regression model for high suicidality (stratum: country)

\begin{tabular}{|c|c|c|c|c|c|c|}
\hline Values & Crude OR $(95 \% \mathrm{Cl})$ & Wald & $p$ value & Adjusted OR† $(95 \% \mathrm{Cl})$ & Wald & $\mathrm{p}$ value \\
\hline Age & $0.98(0.97-1.00)$ & 3.390 & 0.066 & $0.99(0.97-1.01)$ & 1.783 & 0.182 \\
\hline Sex: Female & $1.55(0.98-2.45)$ & 3.552 & 0.059 & $1.36(0.80-2.30)$ & 1.304 & 0.254 \\
\hline \multicolumn{7}{|l|}{ Education } \\
\hline None or primary & 1 & 2.704 & 0.259 & & & \\
\hline Secondary or vocational & $1.78(0.89-3.55)$ & 2.651 & 0.104 & & & \\
\hline College & $1.72(0.81-3.69)$ & 1.976 & 0.160 & & & \\
\hline \multicolumn{7}{|l|}{ Marital status } \\
\hline Married or co-habiting & 1 & 3.487 & 0.175 & & & \\
\hline Widowed or divorced & $1.29(0.68-2.45)$ & 0.628 & 0.428 & & & \\
\hline Never married & $1.56(0.97-2.50)$ & 3.406 & 0.065 & & & \\
\hline \multicolumn{7}{|l|}{ Religion } \\
\hline No religion & 1 & 3.259 & 0.660 & & & \\
\hline Buddhist & $1.39(0.75-2.56)$ & 1.099 & 0.294 & & & \\
\hline Christian & $1.19(0.61-2.36)$ & 0.262 & 0.609 & & & \\
\hline Hindu & $0.46(0.05-3.91)$ & 0.511 & 0.475 & & & \\
\hline Muslim & $1.23(0.33-4.60)$ & 0.097 & 0.755 & & & \\
\hline Others & $0.35(0.04-2.99)$ & 0.929 & 0.335 & & & \\
\hline \multicolumn{7}{|l|}{ Work status } \\
\hline Employed & 1 & 6.565 & 0.038 & 1 & 7.397 & 0.025 \\
\hline Homemaker or student & $1.60(0.96-2.66)$ & 3.309 & 0.069 & $1.22(0.69-2.16)$ & 0.452 & 0.502 \\
\hline Unemployed & $2.03(1.15-3.59)$ & 5.920 & 0.015 & $2.54(1.29-5.01)$ & 7.247 & 0.007 \\
\hline \multicolumn{7}{|l|}{ Past hospitalization } \\
\hline None & 1 & & & & & \\
\hline Presence & $3.39(1.76-6.54)$ & 13.305 & $<0.001$ & $2.90(1.38-6.07)$ & 7.948 & 0.005 \\
\hline MADRS score & $1.13(1.09-1.17)$ & 51.005 & $<0.001$ & $1.10(1.06-1.14)$ & 22.354 & $<0.001$ \\
\hline GSI (of SCL-90-R) score & $1.11(1.07-1.15)$ & 30.439 & $<0.001$ & $1.04(1.00-1.09)$ & 3.269 & 0.071 \\
\hline FSS score & $1.36(1.15-1.61)$ & 12.827 & $<0.001$ & $1.09(0.90-1.32)$ & 0.813 & 0.367 \\
\hline MSPSS score & $0.78(0.67-0.91)$ & 9.993 & 0.002 & $0.84(0.71-1.00)$ & 3.748 & 0.053 \\
\hline
\end{tabular}

OR, odds ratio; Cl, confidence interval; MADRS, Montgomery-Åsberg Depression Rating Scale; Global Severity Index (SCL-90-R, Symptoms Checklist Questionnaire-90-Revised excluding the depression subscale); FSS, Fatigue Severity Scale; MSPSS, Multidimensional Scale of Perceived Social Support. ${ }^{*} P<0.05$.

**P $<0.01$.

†Adjusted variables: $p<0.1$ in univariate analysis.

or Muslim had a lower suicidality, which was shown to be consistent with previous reports that practicing a religion that forbids suicide, such as Islam, contributes to low suicide rates [2,5]. However, the relationship between religion and suicidality was not significant after stratifying the effect of country; thus, no independent effect of religion on suicidality was evident. There was a higher proportion of females than males in the high suicidality group [33-36]. Previous studies have revealed higher suicidality in females in Asian countries than in females in countries such as the United States and Australia [33-36]. This difference could be related to the low socioeconomic status of women, presence of abusive family relationships, and the frequent use of violent suicide methods in Asian countries [33-36].
Unemployed persons had a 2.5 times higher risk of being in the high suicidality group than employed persons. This indicates a need for social structural efforts to improve employment stability in addition to clinical interventions to lower the suicide rate [37].

The high suicidality group had more severe depression, indicated by higher MADRS scores, than the low suicidality group, and reported a greater number of psychiatric. This corresponds with existing arguments that depression severity and other comorbid conditions are crucial risk factors for suicide [9-12,18]. Further, perceived social support, assessed using the MSPSS, served as a protective factor for suicidality. According to the present results, patients who perceived a low level of support from family, friends, and 
significant others had a higher risk of being in the high suicidality group. The importance of social support for suicide prevention has been suggested many times in previous studies [9,11,38], and may be particularly important in the family-oriented Asian culture, where individuals with mental illness have a tendency to be hidden and isolated from society because the stigma of mental illness affects the entire family [39]. Social support should therefore be regarded as an important factor for preventing suicide, and interventions based on social relationships should be expanded in Asian countries. It is interesting that although perceived social support was a protective factor for suicidality, marital status had no significant influence on suicidality. Existing research has shown that marital status or the presence of a partner is not a protective factor for suicide in Asian countries because of the characteristics of the family system in Asian countries $[2,40]$. Many Asians tend to stay married due to gender inequalities and the negative perception of divorce in Asian society, but stressful martial relationships may worsen depression or increase the suicidality $[2,40]$.

Age [9], education [13], and sex, which have all been found to be risk factors in previous studies, were not significantly related to suicidality in the logistic regression. This inconsistency may be due to the differences in subject characteristics, ethnicities and assessment tools. Age effects could not be detected as they are not linear within the range of age reported.

It is possible that suicidality was underestimated due to bias in self-reports, as patients may be embarrassed to admit suicidal behavior and mental problems. Additionally, the samples may not have been representative of each country as a whole, as they comprised clinical samples drawn from tertiary care centers. Recruitment was biased toward MDD patients who used health care institutions, and there may be differences in health care systems among the six countries that participated in the study. Also, This study was crosssectional in design, making it impossible to identify a casual relationship between the identified risk factors and suicidality. Specific risk factors that contributed to the national differences in suicidality risk among MDD patients were not examined. Finally, while impact of country and religion were investigated in the present study, influence of ethnicity was not explored due to homogeneity in terms of ethnicity in most countries. A recent epidemiological study in Malaysia $(n=20,552)$ by Maniam et al. (2013) showed that suicidal ideation was significantly associated with Indian ethnicity (especially among those who were Hindu) compared with Malays and Chinese [41,42]. Further study about the influence of ethnicity on suicidality may be needed in the clinical as well as the general population. Despite these limitations, the present study revealed that a variety of sociodemographic and clinical factors were associated with high suicidality in MDD patients from six Asian countries. In particular, as with severity of MDD, non-clinical features such as social support from various sources were found to be associated with suicidality. This association with cultural and social factors may explain the limited relationship between MDD rate and suicidality in Asian countries. Further, identification of these factors may facilitate the identification of MDD patients at risk of suicide and the provision of suicide prevention guidelines.

\section{Conclusion}

It is well-known that Asian countries have high suicide rates. In addition, the profiles of risk and protective factors of suicide in Asian countries may differ from those of Western countries. However, comprehensive investigation of the characteristics of suicide in the countries was relatively few. This study aimed to examine the sociodemographic and clinical factors associated with suicidality in MDD patients from six Asian countries. The high suicidality group was found to have higher depressive symptoms, general psychopathology and disability scores and lower quality of life and social support scores than the low suicidality group. Moreover, some religion, unemployment and past psychiatric hospitalization were associated with high suicidality in MDD patients in Asian countries. These findings point to the need for a careful evaluation of the risk factors for the suicidality in Asian countries. These factors may facilitate the identification of MDD patients at risk of suicide.

\section{Competing interests}

The authors declare that they have no competing interests.

\section{Authors' contributions}

$\mathrm{AL}$ and $\mathrm{AL}$ participated in data analysis and drafted the manuscript. $\mathrm{CL}$ and $\mathrm{DB}$ carried out data analysis. All other authors participated in the design of the study and collected raw data. All authors read and approved the final manuscript.

\section{Acknowledgements}

This study was supported by an unrestricted research grant from H.Lundbeck A/S and from the Duke-National University of Singapore Office of Clinical Research. This study was also supported by a grant of the Korean Health Technology R\&D Project, Ministry of Health \& Welfare, Republic of Korea (A120051). This study is the work of the MD RAN (The Mood Disorders Research Asian \& Australian Network), which comprises the following members (in alphabetical order of family name [in capital letters]): Jae Nam BAE (Korea), Dianne BAUTISTA (Singapore), Edwin CHAN (Singapore), Sung-man CHANG (Korea), Chia-hui CHEN (Taiwan), CHUA Hong Choon (Singapore), Yiru FANG (China), Tom GEORGE (Australia), Ahmad HATIM (Malaysia), Yanling HE (China), Jin Pyo HONG (Korea), Hong Jin JEON (Korea), Augustus John RUSH (Singapore), Tianmei SI (China), Manit SRISURAPANONT (Thailand), Pichet UDOMRATN (Thailand) and Gang WANG (China).

\section{Disclosure statement}

Dr Hatim has received the grant and support for travel from Lundbeck for this study; lecture fee from Eli Lilly, Pfizer, Janssen, Sanofi Aventis, Lundbeck and Astra Zeneca. He has served as a advisory board member for Pfizer and Otsuka; grants from Lundbeck and Pfizer; Dr CY Liu has served a advisory board member for Eli Lilly. And she has received grants from Eli Lully and Otsuka; speaker fee, travel expense and payment for development of educational presentation from Astrazeneca, Eli Lilly, Janssen, Otsuka, Pfizer. Dr Uomratn has received the support for travel from Lundbeck for this study. Dr Bautista has received research grant from Singapore national medical research council; travel support from Lundbeck for this study; lecture fee from Merck. Dr. Chan has received research grant from Singapore national medical research council, travel support from Lundbeck. Dr. Tian-mei has 
received the support for travel from Lundbeck for this study. Dr Chua has received the support for travel from Lundbeck for this study. Dr Hong has received the grant and support for travel from Lundbeck for this study. He has served a consultant for Servier; the grant from Lundbeck, GlaxoSmithKline, Pfizer. For all remaining authors, no conflicts of interest exist.

\section{Author details}

${ }^{1}$ Department of Psychiatry, Asan Medical Center, Ulsan University College of Medicine, Seoul, South Korea. ${ }^{2}$ Department of Psychological Medicine, Faculty of Medicine, University of Malaya, Kuala Lumpur, Malaysia. ${ }^{3}$ Peking University Institute of Mental Health, Beijing, China. ${ }^{4}$ Department of Psychiatry, Chang Gung Medical Center and Chang Gung University, Tao-Yuan County, Taiwan. ${ }^{5}$ Department of Psychiatry, Depression Center, Samsung Medical Center, Sungkyunkwan University School of Medicine, Seoul, South Korea. ${ }^{6}$ Department of Psychiatry, Faculty of Medicine, Prince of Songkla University, Songkhla, Thailand. 'Tingapore Clinical Research Institute, Singapore, Singapore. ${ }^{8}$ Duke-National University of Singapore, Singapore, Singapore. ${ }^{9}$ Department of Psychiatry, Mackay Memorial Hospital, New Taipei City, Taiwan. ${ }^{10}$ Institute of Mental Health, Woodbridge Hospital, Singapore, Singapore.

Received: 16 December 2013 Accepted: 5 February 2014

Published: 13 February 2014

\section{References}

1. Beautrais AL: Suicide in Asia. Crisis 2006, 27(2):55-57.

2. Chen YY, Wu KC, Yousuf S, Yip PS: Suicide in Asia: opportunities and challenges. Epidemiol Rev 2012, 34(1):129-144.

3. Mental health - Suicide prevention (SUPRE). http://www.who.int/mental_ health/prevention/suicide_rates/en/

4. Yip PSF: Suicide in Asia: causes and prevention. Hong Kong: Hong Kong University Press; 2008.

5. Hendin H, Vijayuakumar L, Bertolote J, Wang H, Phillips M, Pirkis J: Epidemiology of Suicide in Asia. In Suicide and suicide prevention in Asia. edn. Edited by Hendin $\mathrm{H}$, Phillips M, Vijayakumar L, Pirkis J, Wang H, Yip P, Wasserman D, Bertolote J, Fleischmann A. Geneva: Dept. of Mental Health and Substance Abuse, World Health Organization; 2008:7-18.

6. World Health Organization: Towards evidence-based suicide prevention programmes. Manila, Philippines: World Health Organization, Western Pacific Region; 2010.

7. Bradvik L, Mattisson C, Bogren M, Nettelbladt P: Long-term suicide risk of depression in the Lundby cohort 1947-1997-severity and gender. Acta Psychiatr Scand 2008, 117(3):185-191.

8. Isometsa ET, Henriksson MM, Aro HM, Heikkinen ME, Kuoppasalmi Kl, Lonnqvist JK: Suicide in major depression. Am J Psychiatry 1994, 151(4):530-536.

9. Sokero TP, Melartin TK, Rytsala HJ, Leskela US, Lestela-Mielonen PS, Isometsa ET: Suicidal ideation and attempts among psychiatric patients with major depressive disorder. J Clin Psychiatry 2003, 64(9):1094-1100.

10. Malone KM, Haas GL, Sweeney JA, Mann JJ: Major depression and the risk of attempted suicide. J Affect Disord 1995, 34(3):173-185.

11. Sokero TP, Melartin TK, Rytsala HJ, Leskela US, Lestela-Mielonen PS, Isometsa ET: Prospective study of risk factors for attempted suicide among patients with DSM-IV major depressive disorder. Br J Psychiatry 2005, 186:314-318.

12. Holma KM, Melartin TK, Haukka J, Holma IA, Sokero TP, Isometsa ET: Incidence and predictors of suicide attempts in DSM-IV major depressive disorder: a five-year prospective study. Am J Psychiatry 2010, 167(7):801-808.

13. Suppapitiporn S: The predictors of suicidal attempt in depressed patients. Bangkok: Chulalongkorn University; 2002

14. Chan LF, Maniam T, Shamsul AS: Suicide attempts among depressed inpatients with depressive disorder in a Malaysian sample. Psychosocial and clinical risk factors. Crisis 2011, 32(5):283-287.

15. Perroud N, Baud P, Mouthon D, Courtet P, Malafosse A: Impulsivity, aggression and suicidal behavior in unipolar and bipolar disorders. J Affect Disord 2011, 134(1-3):112-118.

16. Fava M, Rosenbaum JF, Pava JA, McCarthy MK, Steingard RJ, Bouffides E: Anger attacks in unipolar depression, Part 1: Clinical correlates and response to fluoxetine treatment. Am J Psychiatry 1993, 150(8):1158-1163.

17. Jeon HJ, Peng D, Chua HC, Srisurapanont M, Fava M, Bae JN, Man Chang S, Hong JP: Melancholic features and hostility are associated with suicidality risk in Asian patients with major depressive disorder. J Affect Disord 2013, 148(2-3):368-374.
18. Jeon HJ: Epidemiologic studies on depression and suicide. $J$ Korean Med Assoc 2012, 55(4):322-328.

19. Alonso J, Angermeyer MC, Bernert S, Bruffaerts R, Brugha TS, Bryson H, de Girolamo G, Graaf R, Demyttenaere K, Gasquet I, et al: Prevalence of mental disorders in Europe: results from the European Study of the Epidemiology of Mental Disorders (ESEMeD) project. Acta Psychiatr Scand Suppl 2004, 420:21-27.

20. Srisurapanont M, Hong JP, Tian-Mei S, Hatim A, Liu CY, Udomratn P, Bae JN, Fang Y, Chua HC, Liu Sl, et al: Clinical features of depression in Asia: results of a large prospective, cross-sectional study. Asia-Pacific Psychiatry 2013, 5(4):259-267.

21. Sheehan DV, Lecrubier $Y$, Sheehan KH, Amorim P, Janavs J, Weiller E, Hergueta T, Baker R, Dunbar GC: The Mini-International Neuropsychiatric Interview (M.I.N.I.): the development and validation of a structured diagnostic psychiatric interview for DSM-IV and ICD-10. J Clin Psychiatry 1998, 59(Suppl 20):22-33. quiz 34-57.

22. American Psychiatric Association: Diagnostic and statistical manual of mental disorders. 4th edition. Washington, DC: American Psychiatric Press; 1994.

23. Ahrens $B$, Linden $M$, Zäske $H$, Berzewski H: Suicidal behavior-symptom or disorder? Compr Psychiatry 2000, 41(2):116-121.

24. Roaldset JO, Linaker OM, Bjorkly S: Predictive validity of the MINI suicidal scale for self-harm in acute psychiatry: a prospective study of the first year after discharge. Arch Suicide Res 2012, 16(4):287-302.

25. Montgomery SA, Asberg M: A new depression scale designed to be sensitive to change. Br J Psychiatry 1979, 134:382-389.

26. Derogatis L: SCL-90-R (revised) version manual I. Clinical Psychometric Research Unit. Baltimore, MD: John Hopkins University School of Medicine; 1997.

27. Krupp LB, LaRocca NG, Muir-Nash J, Steinberg AD: The fatigue severity scale. Application to patients with multiple sclerosis and systemic lupus erythematosus. Arch Neurol 1989, 46(10):1121-1123.

28. Ware JE, Snow KK, Kosinski M, Gandek B, New England Medical Center Hospital: Health I: SF-36 health survey : manual and interpretation guide. Boston: Health Institute, New England Medical Center; 1993.

29. Sheehan DV, Harnett-Sheehan K, Raj BA: The measurement of disability. Int Clin Psychopharmacol 1996, 11(Suppl 3):89-95.

30. Zimet GD, Dahlem NW, Zimet SG, Farley GK: The multidimensional scale of perceived social support. J Personality Assess 1988, 52(1):30-41.

31. Jeon HJ, Lee JY, Lee YM, Hong JP, Won SH, Cho SJ, Kim JY, Chang SM, Lee D, Lee HW, et al: Lifetime prevalence and correlates of suicidal ideation, plan, and single and multiple attempts in a Korean nationwide study. $J$ Nerv Ment Dis 2010, 198(9):643-646.

32. Vyssoki B, Praschak-Rieder N, Sonneck G, Bluml V, Willeit M, Kasper S, Kapusta ND: Effects of sunshine on suicide rates. Compr Psychiatry 2012, 53(5):535-539.

33. Meng L: Rebellion and revenge: the meaning of suicide of women in rural China. Int J Soc Welfare 2002, 11(4):300-309.

34. Ji J, Kleinman A, Becker AE: Suicide in contemporary China: a review of China's distinctive suicide demographics in their sociocultural context. Harv Rev Psychiatry 2001, 9(1):1-12.

35. Moller-Leimkuhler AM: The gender gap in suicide and premature death or: why are men so vulnerable? Eur Arch Psychiatry Clin Neurosci 2003, 253(1):1-8.

36. Yip PS, Liu KY: The ecological fallacy and the gender ratio of suicide in China. Br J Psychiatry 2006, 189:465-466

37. Phillips MR, Yang G, Zhang Y, Wang L, Ji H, Zhou M: Risk factors for suicide in China: a national case-control psychological autopsy study. Lancet 2002, 360(9347):1728-1736.

38. Center for Suicide Research and Prevention: Final Report of the Centre of Suicide Research and Prevention. Hong Kong: The University of Hong Kong; 2006.

39. Lauber C, Rossler W: Stigma towards people with mental illness in developing countries in Asia. International review of psychiatry 2007, 19(2):157-178.

40. Gururaj G, Isaac MK, Subbakrishna DK, Ranjani R: Risk factors for completed suicides: a case-control study from Bangalore. India. Inj Control Saf Promot 2004, 11(3):183-191.

41. MANiAM T, Chan L: Half a century of suicide studies-a plea for new directions in research and prevention. Sains Malaysiana 2013, 42(3):399-402.

42. Maniam T, Chinna K, Mariapun J: Suicide prevention program for at-risk groups: pointers from an epidemiological study. Preventive Medicine 2013, 57:S45-S46.

doi:10.1186/1471-244X-14-37

Cite this article as: Lim et al:: Clinical and sociodemographic correlates of suicidality in patients with major depressive disorder from six Asian countries. BMC Psychiatry 2014 14:37. 